\title{
Demanslı Parkinson Hastalarının Bakım Verenlerinde Cinsiyete Göre Yalnızık, Ağrı ve Anksiyete Düzeylerinin Psikometrik Değerlendirilmesi
}

\section{Psychometric Properties of Loneliness, Pain and Anxiety Levels According to Gender Among Caregivers of the Parkinson's Disease Dementia \\ Murat GÜLTEKIN $1{ }^{\mathbb{D}}$, Duygu KURT GÖK $\underline{1} \underset{1}{\mathbb{D}}$, Ayten EKINCi 1}

1 Erciyes Üniversitesi Tıp Fakültesi Nöroloji Anabilim Dalı, Kayseri, Türkiye

Öz.

Amaç: Parkinson hastalığı seyrinde hastaların üçte birinde demans görülmektedir. Buna bağlı olarak bakım veren yükünde artış meydana gelmektedir. Bakım verenlerde sıklıkla görülen yalnızık, kişide depresyon, anksiyete ve somatik ağrı gibi zihinsel ve fiziksel ek risk faktörlerinin gelişmesine zemin hazırlar. Bu çalışmadaki amaç; Parkinson Demansı bakım verenlerinin günlük yaşamlarındaki yalnızık düzeyini ortaya koymak ve bu düzeyin zihinsel (bellek) ve fiziksel (ağıı) yakınmalarıyla ilişkisini belirlemektir.

Materyal ve Metod: Çalışmaya 48 Parkinson demansı bakımveren dahil edildi. Parkinson demansı hastalarının bakım verenlerine UCLA Yalnızlık Ölçeği, Hastane Anksiyete Depresyon Ölçeği (HAD), Öznel Bellek Yakınması Anketi (ÖBYA), Vizuel Analog Skala (VAS) ve Mini Mental Durum Değerlendirme Testi (MMDD) uygulandı.

Bulgular: Bakım verenlerin yaş ortalaması 58.5 olup \%68'i kadın cinsiyette idi. Bakım verenlerin büyük çoğunluğunun hastaların eşleri ve daha az oranda da çocukları olduğu görüldü. Analiz sonuçlarına göre kadın cinsiyetteki bakım verenlerin ağıı ve anksiyete düzeyi, erkek cinsiyetteki bakım verenlerden anlamlı olarak daha yüksek bulundu. Hastaların MMDD puanları ile bakım verenlerin yalnızlık düzeyi ve bakım verme süresi arasında negatif yönde korelasyon belirlendi.

Sonuç: Parkinson demansı bakım verenlerinin büyük çoğunluğunu kadın aile bireyleri oluşturmaktadır. Kadın bakım verenlerde somatik ağrı yakınmaları daha fazla görülmekte ve daha yoğun anksiyete yaşamaktadır. Ayrıca hastalarda demans düzeyinin ilerlemesiyle bakım verenlerin yalnızlık düzeyi artmaktadır.

Anahtar Kelimeler: Parkinson demansı, Bakım veren, Yalnızlık, Ağrı, Anksiyete.

Abstract

Background: In the clinical course of Parkinson's disease, one-third of patients have dementia. This results in an increase in caregiver burden. Loneliness among caregivers often develops, putting caregivers at additional risk for mental and physical health consequences such as depression, anxiety and somatik pain. The aim of this study; to reveal the level of loneliness in daily life of caregivers of Parkinson's Dementia and to determine its relationship with mental (memory) and physical (pain) complaints.

Materials and Methods: Forty-eight Parkinson's dementia caregivers were included in the study. We conducted tests which included UCLA loneliness scale (ULS), hospital anxiety depression scale (HADS), subjective memory complaints questionnaire (SMCQ), visual analog scale (VAS) and mini mental state examination (MMSE) to caregivers of the PD patients.

Results: The caregivers' mean age was 58.52 years and 33 caregivers (68\%) were female. It was found that the female caregivers had significantly higher scores of the HAD-A and VAS tests. A negative correlation was found between the MMSE scores of the patients and the loneliness level of the caregivers and duration of caregiving. Conclusions: The majority of caregivers of Parkinson's dementia are female family members. Female caregivers experience more somatic pain and anxiety than male caregivers. It was seen as the dementia progressed, the level of loneliness of caregivers increased.

Keywords: Parkinson dementia, Caregiver, Loneliness, Pain, Anxiety.

\section{Sorumlu Yazar I \\ Corresponding Author}

Dr. Duygu KURT GÖK

Erciyes Üniversitesi Tıp Fakültesi, Nöroloji Anabilim Dalı, Dr.Turhan Feyzioğlu cad. No:42 38039, Melikgazi/Kayseri.

Tel: 05059226011 ,

e-mail: duygukurt1706@gmail.com

Geliş tarihi / Received:

15.11.2019

Kabul tarihi / Accepted: 13.03.2020

DOI: 10.35440/hutfd.647222 


\section{Giriş}

Parkinson hastalı̆ı $(\mathrm{PH})$ sinsi başlangıçlı ve yavaş seyirli kronik nörodejeneratif bir hastalıktır. Hastalık substantia nigrada dopaminerjik nöronların kaybı sonucu gelişir. Hastalığın görülme sıklığı yaşla birlikte artar (1). Hastalığın doğal seyrinde motor fonksiyonlarda tedrici bozulma gözlenirken, hastaların yaklaşık \% 30-40'unda kliniğe demans tablosu ilave olmaktadır (2). Bu yüzden hastalık ilerledikçe, hastalar bakım verenlerine daha bağımlı hale gelmektedir. Bunun sonucu olarak da hem hasta, hem de bakım verenin yaşam kalitesi ciddi şekilde etkilenmektedir (3).

PH'de görülen demansın klinik profili frontosatriatal özellikler taşır. Alzheimer demansının karakteristik özelliklerinden olan disfaji, disfori, agnozi ve apraksi beklenmezken, klasik olarak görsel halüsinasyonlar, dalgalanan kognitif durum ve viziyospasyal defekt sıktır. İsimlendirme ve konuşma akıcılığında bozulma görülebilir (4). Parkinson demansı (PD) olan hastalarda bakım verenler; ev içi güvenlik önlemleri alınmasında, hastanın tedavi uyumunda ve günlük yaşam aktivitelerinin yerine getirilmesinde büyük önem taşır. Hastanın ilaçlara ve tedaviye yanıtı bakım verenin sağladığı güvenilir bilgiden elde edilir. Bu nedenle bakıclları desteklemek başarılı tedavi yönetimi açısından son derece önemlidir (3).

Çalışmalar sonucunda yalnızlık ve yol açtığı sağlık sonuçları arasında bağlantı olduğu gösterilmiş olmakla beraber, PD bakım verenlerinde yalnızık düzeyi ve bu düzeye katkıda bulunan diğer sosyal, fiziksel ve ruhsal etmenler hakkında daha fazla veriye ihtiyaç olduğu gösterilmiştir (3). Bu alanda yapılacak çalışmalar ile yalnızlık düzeyi ilişkili etmenlerin tespiti sağlanabilir ve yalnızlığı azaltmaya yönelik yeni stratejiler geliştirilebilir.

Ülkemizde de PH bakım veren yaşam kalitesi ve bakıcı yükü üzerine yapılmış çalışmalar olmakla birlikte; PD bakım vereninin yalnızlık düzeyini değerlendiren bir çalışma bulunmamaktadır $(5,6)$. Yalnızlık duygusunun ilişkili olduğu diğer nörolojik, psikolojik ve fiziksel problemlerin ülkemiz koşullarında belirlenmesi ve böylece bakım verenlere gerekli desteğin sağlanması amacıyla bu alanda araştırma yapılmasına intiyaç vardır.

Bu çalışmanın amacı; PD bakım verenlerinin hayat kalitesini olumsuz etkileyen günlük yaşamlarındaki yalnızlık düzeyini ortaya koymak ve bu düzeyin bellek, fiziksel (ağrı) ve ruhsal (depresyon ve anksiyete) yakınmalarla ilişkisini ortaya koymaktır.

\section{Materyal ve Metod}

Katılımcılar, Erciyes Üniversitesi Tıp Fakültesi Nöroloji polikliniğinde takipli, "Parkinson Demansı" tanısı almış hastaların bakım verenleri arasından, araştırma kriterlerini karşılayan gönüllü 48 bakım veren idi. Verilerin toplanmasında, Hastane Anksiyete Depresyon Ölçeği (HAD), UCLA Yalnızlık Ölçeği, Öznel Bellek Yakınması Anketi (ÖBYA),
Vizuel Analog Skala (VAS) ve Mini Mental Durum Değerlendirme (MMDD)' si kullanıldı.

Veriler, çalışmanın amacı hakkında bilgi verilerek ve katııımcıların yazııı onamları alınarak gönüllülük esasına göre elde edildi. Katılımcılar önce demografik bilgi formunu doldurdu. Demografik bilgi formunda yer alan hasta ile ilgili bilgiler bakım verenden yüz yüze görüşme yöntemiyle alındı. İzleyen aşamada bakım verenlere ölçekler uygulandı.

Bu çalışma 20.12.2017 tarih ve 588 numaralı Erciyes Üniversitesi Klinik Araşsırmalar Etik Kurulu tarafından onaylanmıştır.

\section{Veri Toplama Araçları}

Demografik Bilgi Formu: Çalışmanın amacına uygun olarak dahil edilme kriterlerini karşılayan bakım verenlerin ve hastaların yaş, cinsiyet, eğitim düzeyi ve diğer demografik bilgilerine ulaşabilmek amacıyla hazırlanan bir form uygulandı. Mevcut form ile demografik bilgilerin yanında, bakım verenlerin hastaya yakınlık derecesi, günlük bakım verme süresi; hastaların ise Parkinson hastalık süresi ile ilgili klinik bilgileri sorgulanarak kaydedildi.

Hastane Anksiyete Depresyon Ölçeği (HAD): Zigmond ve Snaith tarafından geliştirilen ölçek, anksiyete ve depresyon düzeyini ve şiddet değişimini değerlendirmektedir (7). HAD'ın Türkçe geçerlilik güvenilirlik çalışmasını Aydemir, Güvenir, Küey ve Kültür 1997'de yapmıştır (8). Ölçek maddelerinin yarısı (tek sayılı) anksiyeteyi ve kalan yarısı (çift sayilı) depresyonu ölçmekte olup 14 sorudan oluşmaktadır. Cevapların 0-3 arasında değiştiği dörtlü Likert tipi bir ölçektir. Alt ölçeklerden alınabilecek en düşük puan 0 , en yüksek puan 21'dir.

\section{Mini Mental Durum Değerlendirme (MMDD)}

Folstein ve arkadaşları tarafından 1975 'de geliştirilen test, yönelim, kayıt hafızası, dikkat-hesaplama, hatırlama ve lisan olmak üzere beş bilişsel alanı değerlendirmektedir (9). Türkçe geçerlilik güvenilirlik çalışması Güngen tarafından yapıımıştır (10). Ölçekten alınabilecek en düşük puan 0 , en yüksek puan 30'dur. MMDD değerlendirmesine göre 24 puan altı bozuk olarak değerlendirilmektedir.

Öznel Bellek Yakınmaları Anketi (ÖBYA): Youn ve arkadaşları tarafından öznel bellek yakınmalarını değerlendirmek için geliştirilmiştir (11). Anket, 4'ü genel bellek, 10'u ise günlük bellek işlevlerini değerlendiren, "evet-hayır" şeklinde yanıtlanan toplam 14 maddeden oluşmaktadır. Anketin Türkçe formunun geçerlik ve güvenirlik çalışması ise HBB ve sağlıklı yaşlı gruplarında Özel-Kızıl ve arkadaşları tarafından yapılmışı̧ı (12).

\section{Vizuel Analog Skalası (VAS)}

Ölçek, ağrının sayısal olarak da değerlendirilebilmesi için Benedetti ve arkadaşları tarafından 1991'de geliştirilmiştir (13). Kişinin hissettiği (öznel) ağrı şiddetini belirlemek amacıyla kullanılmaktadır. $10 \mathrm{~cm}$ uzunlukta "Ağrı yok" ile başlayıp "Dayanılmaz ağrı" ile biten bir hattan oluşan bir cet- 
veldir. Birey ağrısının şiddetini, bu hat üzerinde uygun gördüğü yerde işaretle belirtir.

\section{UCLA-Yalnızlık Ölçeği}

Bireylerin yalnızlık algılarını değerlendirmek amacıyla Russell ve arkadaşları tarafından geliştirilmiştir (14). Ölçeğin Türkçe geçerlilik ve güvenilirlik çalışmasını Yaparel 1984'te yapmıştır (15). Maddeler puanlanırken "Hiç Yaşamam = 4 puan", "Nadiren Yaşarım = 3 puan", "Bazen Yaşarım = 2 puan" ve "Sık Yaşarım = 1 puan" olarak hesaplanmaktadır.

\section{İstatistik}

Verilerin değerlendirilmesinde SPSS 21 istatistik paket programı kullanıldı. Ölçeklerden elde edilen puanların bakım verenlerde cinsiyet değişkenine göre farklılaşıp farklılaşmadığını belirlemek için bağımsız gruplar için t-test uygulandı. Bakım verenlerin ölçek puanları üzerinden değişkenler arasında bir ilişki olup olmadığını görmek üzere Pearson Momentler Çarpımı korelasyon analizi uygulandı.

\section{Bulgular}

Çalışmaya 48 bakım veren dahil edildi. Bunların 33'ü (\%68.8) kadın cinsiyette idi ve bakım verenlerin ortalama yaşı $58.52 \pm 13.29$ olarak bulundu. Hastaların ortalama hastalık süresi 9.23 yıldı. Bakım verenlerin çoğunun, hastaların eşleri (\%68.8) ya da çocukları (\%25.0) olduğu saptandı. Çalışmaya dahil edilen bakım verenlerin temel demografik verileri Tablo 1'de gösterilmektedir.

Tablo 1. Bakım Verenler ve Hastaların Demografik Özellikleri

\begin{tabular}{|c|c|c|c|c|}
\hline \multirow[b]{2}{*}{$\mathrm{N}=48$} & \multicolumn{2}{|c|}{ Bakım veren } & \multicolumn{2}{|r|}{ Hasta } \\
\hline & $n$ & $\%$ & $n$ & $\%$ \\
\hline \multicolumn{5}{|l|}{ Cinsiyet } \\
\hline Kadın & 33 & 68.8 & 16 & 33.3 \\
\hline Erkek & 15 & 31.3 & 32 & 66.7 \\
\hline \multicolumn{5}{|l|}{ Eğitim Düzeyi } \\
\hline Okur-yazar değil & 9 & 18.8 & 16 & 33.3 \\
\hline İlkokul & 25 & 52.1 & 21 & 43.8 \\
\hline Ortaokul-Lise & 11 & 22.9 & 8 & 16.7 \\
\hline Üniversite & 3 & 6.3 & 3 & 6.3 \\
\hline \multicolumn{5}{|l|}{ Ek Hastalık } \\
\hline Var & 24 & 50.0 & 29 & 60.4 \\
\hline Yok & 24 & 50.0 & 19 & 39.6 \\
\hline \multicolumn{5}{|l|}{ Yakınlık } \\
\hline Eş & 33 & 68.8 & & \\
\hline Çocuk & 12 & 25.0 & & \\
\hline Diğer* & 3 & 6.3 & & \\
\hline \multicolumn{5}{|c|}{ Ortalama (Standart Sapma) } \\
\hline Yaş & & $.52( \pm 13.29)$ & & $70.94( \pm 7.12)$ \\
\hline Bakım verme saati & & $3.65( \pm 2.74)$ & & \\
\hline Parkinson Süresi & & & & $9.23( \pm 6.37)$ \\
\hline MMDD & & $6.42( \pm 2.70)$ & & $18.36( \pm 4.70)$ \\
\hline
\end{tabular}

Kadın ve erkek cinsiyetteki bakım verenlerde ölçeklerden alınan puanlar arasındaki fark incelendiğinde; HAD-A ve VAS puanları kadın cinsiyette bakım verenlerde HAD-A skoru erkek cinsiyetteki bakım verenlerden istatistiksel açıdan anlamlı ölçüde yüksek olarak bulundu.

Ancak HAD-D, UCLA, ÖBYA ve MMDD puan ortalamaları açısından cinsiyete göre gruplar arasında farklılık saptanmadı. Sonuçlar Tablo 2' de gösterilmektedir.

Tablo 2. Ölçek Puanlarına İlişkin t-test Sonuçları

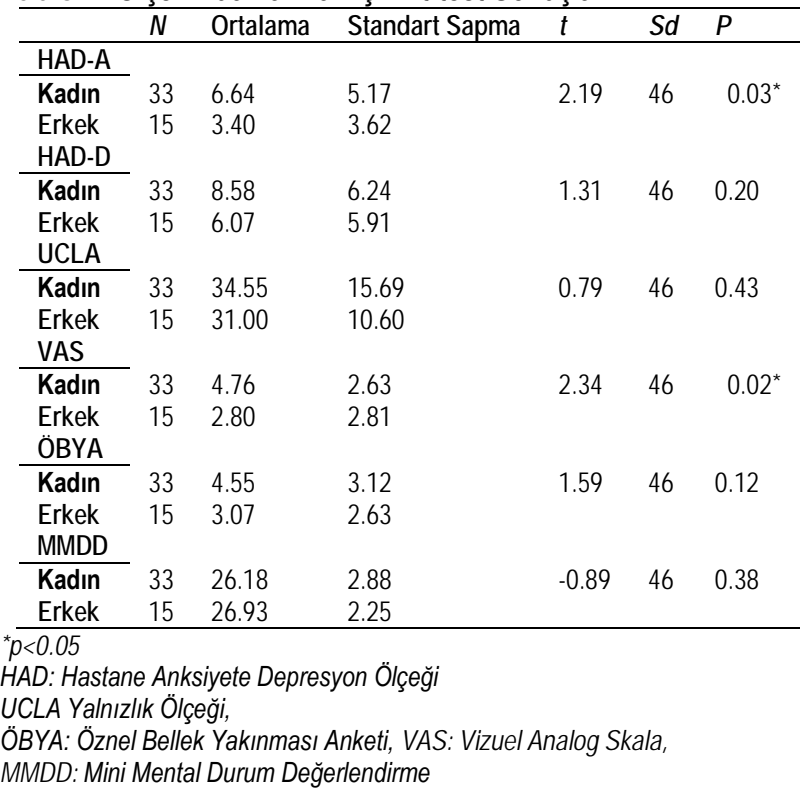

Bakım verenlerin yalnızı ık düzeyi ile ağrı, bellek yakınması, anksiyete ve depresyon düzeyi arasındaki ilişki incelenediğinde; Analiz bulguları tüm ölçek puanlarının birbiri ile pozitif yönde ilişkili olduğunu gösterdi. Bulgular incelendiğinde, yalnızlık ile ağrı arasında pozitif yönde orta düzeyde $(r=0.39, p<0.01)$, yalnızlık ile öznel bellek yakınması arasında pozitif yönde orta düzeyde $(r=0.48, p<0.01)$, yalnızIık ile anksiyete arasında pozitif yönde orta düzeyde $(r=0.45, p<0.01)$ ve yalnızlık ile depresyon arasında pozitif yönde orta düzeyde $(r=0.58, p<0.01)$ anlamlı ilişki olduğu görüldü. Bu sonuçlar Tablo 3'de gösterilmektedir.

Tablo 3. Ölçek Puanlarına İlişkin Korelasyon Matrisi

\begin{tabular}{|c|c|c|c|c|c|}
\hline & 1 & 2 & 3 & 4 & 5 \\
\hline 1.UCLA Yalnızlık Ölçeği & - & & & & \\
\hline 2.VAS & $0.39 \star *$ & - & & & \\
\hline 3.ÖBYA & $0.48^{\star *}$ & $0.47^{* *}$ & - & & \\
\hline 4.HAD-A & $0.45^{\star \star}$ & $0.56^{\star *}$ & $0.47^{\star *}$ & - & \\
\hline 5.HAD-D & 0.58 ** & $0.52^{\star *}$ & $0.62^{\star *}$ & $0.71^{\star \star}$ & - \\
\hline \multicolumn{6}{|c|}{$\begin{array}{l}{ }^{* *} p<0.01 \\
H A D: \text { Hastane Anksiyete Depresyon Ölçeği } \\
\text { UCLA Yalnızlık Ölçeği, } \\
\text { ÖBYA: Öznel Bellek Yakınması Anketi, VAS: Vizuel Analog Skala, }\end{array}$} \\
\hline \multicolumn{6}{|c|}{$\begin{array}{l}\text { Tablo 4. UCLA Yalnızlık Ölçeği, Hastaların MMDD Skoru ve Ba- } \\
\text { kım Süresine İlişkin Korelasyon Matrisi }\end{array}$} \\
\hline & & 1 & 2 & & 3 \\
\hline 1.UCLA Yalnızlık Ölçeği & & - & & & \\
\hline 2. MMDD & & $-.58^{\star \star}$ & - & & \\
\hline 3. Bakım Süresi & & $0.65^{\star *}$ & -.72 & & - \\
\hline
\end{tabular}

${ }^{* *} p<0.01$

MMDD: Mini Mental Durum Değerlendirme

Hastaların MMDD skoru ile bakım verme süresi ve bakım verenlerin yalnızlık düzeyi arasındaki ilişki incelendiğinde, 
MMDD skoru ile UCLA yalnızlık ölçeği ve bakım verme süresinin negatif yönde ilişkili olduğu gösterildi. Yani hastaların demans evresi ilerledikçe bakım verenlerin yakınları için ayırdıkları süre ve yalnızlık ölçek puanları artmaktaydı. Sonuçlar ise Tablo 4'de gösterilmektedir.

\section{Tartışma}

$\mathrm{Bu}$ araştırmamızda, $\mathrm{PD}$ hastası bakım verenlerinin günlük yaşamlarındaki yalnızlık düzeyi ve bu düzeyin zihinsel (bellek) ve fiziksel (ağıı) yakınmalarılla ilişkisi belirlendi. Özellikle kadın bakım verenlerin anksiyete ve ağıı düzeyinin erkek bakım verenlerden anlamlı olarak yüksek olduğu saptandı. Parkinson demansı ilerledikçe bakım verenlerin yalnızlık düzeyinde artış olduğu gösterildi.

Parkinson hastalığı ileri yaşla birlikte sıklığı artan kronik nörodejeneratif bir hastalıktır. Hastalık ilerledikçe hastaların bağımsız olarak günlük yaşam aktivitelerini sürdürebilme yetenekleri azalmaktadır. Hastaların \% 30-40'nda zamanla tabloya demansiyel bulgular eklenmekte ve bu durum hem hasta, hem de bakım verenin yaşam kalitesini olumsuz etkilemektedir $(3,4,16)$. Daha önce yapılmış çalışmalarda hastaların bakımının çok büyuik bir bölümünün kadınlar tarafından üstlenildiğ gösterilmiştir $(6,17,18)$. Bakım verenlerin büyük çoğunluğunu tüm toplumlarda sıklıkla eş, daha sonra çocuklar oluşturmaktadır (19-21). Bizim çalışmamızda da bakım verenlerin \%68'i eş, \%25'i çocuklardan oluşmuştur. Ayrıca bakım verme sorumluluğunu daha çok kadınlar üstlenmiştir (\%68.8). Bu durum sosyokuiltürel yapı ile ilişskili olmalıdır.

Kadın cinsiyetin emosyonel açıdan daha duyarlı olması sebebi ile yalnızık düzeyinin kadın bakım verenlerde daha fazla olacağı öngörülmüştür. Bir çalışmada kronik hastalıklarda bakım veren bireylerde cinsiyete göre yalnızlık düzeyleri değerlendirimiş ve kadınlarda daha fazla bulunmuştur (22). Ancak bizim çalışmamızda bakım veren kişilerin cinsiyete göre yalnızlık ölçeği puanları arasında fark saptanmadı. Bu durum çalışmamıza dahil edilen örneklem boyutuyla ilişkili olabilir. Dereli ve ark. yaptığı çalışmada yalnızlık düzeyinin cinsiyet grupları arasında farklılaşmadığı bildirilmiştir (23). Jones ve ark. yaptığı çalışmada PD kadın ve erkek bakım verenler arasında bakım yükü katsayısının cinsiyete göre fark etmediği, bakım yuikü katsayısı ile bakım süresinin ve bakım yükü katsayısı ile hastalığn evrelerinin dogru orantılı oldugu görülmüştür (24). Bizim çalışmamızda da özellikle uzun bakım verme süresi ve düşük MMDD sonuçlarının yalnızılk düzeyini artırdığı bulunmuştur. Bu durum hastada izlenen demansiyel süreç ilerledikçe, daha fazla bakım verme süresinin harcandığı ve bakım verenin sosyal izolasyonunun artarak yalnızlık düzeyinin arttığı şeklinde yorumlanmıştır

Türkiye'de yapılmış Parkinson bakım verenlerinde bakım yükü katsayısının cinsiyete göre değerlendirildiği çalışmada ise bakım veren kișinin yașının, cinsiyetinin ya da hastanın cinsiyetinin, bakım yuikü katsayısına doğrudan etkisi olmadığı bildirilmiştir (5). Bizim çalışmamızda ise anksiyete ve ağrı yakınmalarının kadın bakım verende erkek bakım verenden daha fazla olduğu görülmüştür. Bakım verenlerin anksiyete ve depresyon açısından değerlendirilmesi sonucunda HAD-A skorları kadınlarda erkek bakım verenlere oranla anlamlı ölçüde yüksek elde edildi. Bu sonuç, Parkinson hastası olan fakat kognitif bozulma eşlik etmeyen hastaların bakım verenlerinin araştırıldığı bir başka çalışmada da erkek bakım verenlerin stres düzeyinin kadınlardan daha az olduğu şeklinde vurgulanmış, kadınlarda anksiyete bulgularının erkeklerden daha fazla olduğu gösterilmiştir (25).

Çalışmamızda bakım verenlerin yalnızlık düzeyi ile ağrı, anskiyete, depresyon ve bellek yakınmalarının varlığı orta düzeyde ilişkili bulundu. Yalnızık düzeyi arttıkça bellek yakınmaları artmakta, depresif semptomlar, kaygı ve ağrı yakınmaları artmaktadır. Daha önce yapılmış çalışmalarda Alzheimer hastası bakım verenlerinde yalnızlık ve depresyon arasında güçlü bir ilişki olduğu gösterilmiştir $(26,27)$. Aynı biçimde yalnızıı̆ın bakım verenlerde bellek yakınmalarını kötüleştirdiği, bakım verenlerin bellek kapasitelerinin daha kötü olduğu ve bunun yalnızlık düzeyi ile ilişkili olduğu konusunda benzer sonuçlar literatürde gösterilmiştir (28). Bu çalışmanın kısıtlı yönü; çalışmamızın benzer yaş gruplarında ve bakım verme rolü üstlenmeyen kontrol grubu içermemesi, ayrıca çalışmaya alınan bakım veren sayısının nispeten az ve yalnızca belirli bir bölgeye sınırlı olmasıdır. Güçlü yönü ise Türkiye'de PD bakım verenlerinde yalnızık ve ilişkili durumları değerlendiren ve bu konuda ülkemiz için kullanılabilir verileri sağlayan ilk çalışma olmasidır.

Sonuç olarak; Parkinson hastalarının takip ve tedavisini yöneten hekimler hasta ile birlikte bakım vereni de değerlendirmelidir. Bakım veren bireylerde gelişebilecek anksiyete, yalnızlık, depresyon gibi semptomların erken farkına varmalı ve gerekli desteği sağlayarak hem bakım verenin sağlığı hem de hastanın yaşam kalitesine olumlu katkıda bulunabilmelidir.

Etik Onam: Bu çalışma 20.12.2017 tarih ve 588 numaralı Erciyes Üniversitesi Klinik Araştırmalar Etik Kurulu tarafindan onaylanmıştır.

\section{Kaynaklar}

1. Mhyre TR, Boyd JT, Hamill RW, Maguire-Zeiss KA.Parkinson's Disease. Subcell Biochem. 2012;65:389-455.

2. Aarslan D, Zaccai J, Brayne C. A systematic review of prevalence studies of dementia in Parkinson's disease. Mov Disord. 2005; 20(10):1255.

3. McRae C, Fazio E, Harsock G, Kelley L, Urbanski S, Russel D. Predictor of loneliness in caregivers of persons with Parkinson's disease. Parkinsonism Relat Disord. 2009;15(8):554-557.

4. Emre M, Aarsland D, BrownR, Burn DJ, Duyckaerts C, Mizuno Y et all. Clinical diagnostic criteria for dementia associated with Parkinson's disease. Mov Disord. 2007; 22(12): 1689-707. 
5. Yüksel, G., Varlıbas, F., Karlıkaya, G., Sııka, Y., Tireli, H. Parkinson Hastalığnda Bakıcı Yưkü. Parkinson Hastalıgı ve Hareket Bozuklukları Dergisi. 2007; 10(1-2), 26-34.

6. Özdilek B. Parkinson hastalığında motor ve motor olmayan bulguların bakım verenin yaşam kalitesi ve külfet düzeylerine etkisinin değerlendirilmesi. Uzmanlık Tezi, İstanbul: Marmara Üniversitesi Tıp Fakültesi, 2008.

7. Zigmond AS, Snaith PR. The Hospital Anxiety and Depression Scale. Acta Psychiatr Scand. 1983;67(6):361- 370.

8. Aydemir Ö, Güvenir T, Küey L, Kültür S. Hastane anksiyete ve depresyon ölçeği Türkçe formunun geçerlilik ve güvenilirliği. Türk Psikiyatri Dergisi. 1997;8(4): 280-287.

9. Folstein MF, Folstein SE, McHugh PR. "Mini Mental State" A practical method for grading the cognitive state of patients for the clinician. J Psychiatr Res. 1975;12(3):189-198.

10. Güngen C, Ertan T, Eker E, Yaşar R, Engin F. Reliability and Validity of The Standardized Mini Mental State Examination in The Diagnosis of Mild Dementia in Turkish Population. Türk Psikiyatri Dergisi. 2002; 13(4):273-281.

11. Youn JC, Kim KW, Lee DY, Jhoo JH, Lee SB, Park JH.et all. Development of the Subjective Memory Complaints Questionnaire. Dement Geriatr Cogn Disord. 2009; 27(4): 310- 317.

12. Özel-Kızıl ET, Duman B, Alııntaş Ö, Kııııı S, Baştuğ Z, Baran U.Öznel Bellek Yakınmaları Anketi Türkçe Formunun Psikometrik Özelliklerinin Değerlendirilmesi. Türk Geriatri Dergisi. 2013; 16:150-154.

13. Benedetti C, Butler S. Systemic Analgesics. 2nd Edit Vol.1 Lea and Febiger, Philadelphia, PA:Lea\&Febiger 1990:1640-1675.

14. Russell D, Peplau LA, Ferguson ML. Developing a measure of loneliness. J Pers Assess. 1978; 42(3): 290-294.

15. Yaparel. R. Sosyal İlişkilerdeki Basarı ve Başarısızlık Nedenlerinin Algılanması ile Yalnızlık Arasındaki Bağlantı. Yayınlanmamış Yüksek Lisans Tezi, Ankara: Hacettepe Üniversitesi, 1984.

16. Martinez-Martin P, Arroyo S, Rojo-Aubin JM, Rodriquez-Blazquez C, Frades B, Cuesta JP et all. Burden, Perceived Health Status, and Mood Among Caregivers of Parkinson's Disease Patients. Mov Disord. 2008; 23(12);1673-1680.

17. Grün D, Pieri V, Vaillant $M$, Diederich NJ. Contributory Factors to caregiver burden in Parkinson disease. J Am Med Dir Assoc. 2016; 17(7): 626-32.

18. Martinez-Martin $P$, Jeukens-Visser M, Lyons $K$, Rodriguez-Blazquez C, Selai C, Siderowf A et all. Health-related quality-of-life scales in Parkinson's disease: critique and recommendations. Mov Disord. 2011; 26(13): 2371-80.

19. Chiong-Riviero H, Ryan GW, Flippen C, Bordelon Y, Szumski NR, Zesiewicz TA, Vassar S.et all. Patient's and caregivers' experiences of the impact of Parkinson's disease on healt status. Patient Relat Outcome Meas. 2011;2:57-70.

20. Lawson RA, Collerton D, Taylor JP, Burn DJ, Brittain KR. Coping with cognitive Impairment in people with Parkinson's disease and their carers: a qualitative study. Parkinson's disease. 2018. Doi:10.1155/2018/1362053.

21. Bhimani R. Understanding the burden on caregivers of people with Parkinson's: a coping review of the literature. Rehabill Res Pract. 2014; 2014:718527.Doi:10.1155/2014/718527.

22. Gök Uğur H, Orak OS, Başköy F, Serdaroglu S, Küçüköner Ö. Investigation of the relationship between the levels of loneliness and soclal support perceived by caregivers of bedridden patients. The Journal of Internatıonal Social Research. 2015;8(36):958-967.

23. Dereli F, Koca B, Demircan S, Tor N. Bir huzurevinde kalan yaşlıların yalnızlık düzeylerinin incelenmesi. Yeni Tıp Dergisi. 2010;27:93-97. 24. Jones AJ, Kuijer RG, Livingston L, Myall D, Home K, MacAskill M et all. Caregiver burden is increased Parkinson's disease with mild cognitive impairment. Translational Neurodegeneration. 2017;6:17.

25. Gultekın M, Ekıncı A, Erturk G, Mırza M. Female Parkinsons disease caregivers have much anxiety and depressive symptom. Brain Behav. 2017;7(9):e00787
26. Valimaki THE, Vehvilainen-Julkunen KM, Pietila AM, Pietila TA. Caregiver Depression is Associated with a Low Sense of Coherence and Health-Related Quality of Life. Aging Ment Health. 2009;13(6):799-807. 27. Beeson RA. Loneliness and Depression in Spousal Caregivers of Those With Alzheimer's Disease Versus Non-Caregiving Spouses. Archives of Psychiatric Nursing 2003:135-143.

28. Ekwall AK, Sivberg B, Hallberg IR. Loneliness as a predictor of quality of life among older caregivers. Journal of Advanced Nursing 2005;49(1):23-32. Doi:10.1111/j.1365-2648.2004.03260.x. 